\title{
Production of Green Cement from Slag Enhanced by Egyptian Metakaolin Materials
}

\author{
Abdeen M. El Nagar \\ Housing and Building National Research Centre (HBRC), 87 El-Tahrir St., Dokki, Giza, P.O. Box 11511 Cairo, Egypt. \\ * Corresponding Author: abdeenelnagar@yahoo.com
}

Received: 12-08-2020

Accepted: 12-10-2020

\begin{abstract}
New geopolymer-based materials offer excellent perspectives for the future; they should not be regarded as competitive materials for Portland cement, which has been the reference construction material for so long, but as alternative materials with a series of important advantages to be considered. Metakaolin (MK) produced from firing kaolin material up to $750^{\circ} \mathrm{C}$ for $2 \mathrm{~h}$ with a heating rate of $5^{\circ} \mathrm{C} / \mathrm{min}$; leads to an enhancement in mechanical and microstructural properties of alkali activated geopolymer of water cooled slag material using $(6: 6, \mathrm{wt} \%)$ of sodium hydroxide and sodium silicate. In the present work the ratios of MK which will be added are less than $20 \%$ of the total mass, because of the used MK was very fine with average pore structure less than $30 \mathrm{~m} \mu$, which hinders the geopolymerization reaction if used as high ratio. Curing was performed under $100 \%$ relative humidity at a temperature of $38^{\circ} \mathrm{C}$ and ages of 7, 14, $28 \& 90$ days. The properties of geopolymer specimens have been studied through measurement of XRD, SEM imaging, FTIR, compressive strength and water absorption. Results showed that the mixes of metakaolin up to $15 \%$ results in an enhancement in the mechanical properties as compared with slag control mix up to 90 days.
\end{abstract}

Key words: Geopolymer, kaolin, metakaolin, slag, alkali activation.

\section{Introduction}

Geopolymers can be thought as a new generation binder that can substitute for the calcium silicate hydrate which are essential components of Portland cement, where they have a lower impact on global warming than OPC but on the other side they have a higher environmental impact regarding other impact categories (Davidovits, 1999).

During the last decade, considerable research efforts have been directed towards the development of inorganic geopolymers, due to the wide range of potential applications for these materials. Many reports can be found in the previous works on the synthesis, properties and applications of geopolymers (Steveson \& Sagoe-Crentsil, 2005). It is found that fly ash, one of the most abundant sources for making geopolymer binders and used it till date is very limited (Hardjito et al., 2004). The wide variety of applications of geopolymer includes: fire resistant materials, low energy ceramic tiles, refractory items, cements and concretes (Davidovits, 2008). $\mathrm{MK}$ is a thermally treated product from kaolin, which is one of the naturally occurring abundant minerals in the earth's crust. Kaolin refers to a family of kaolinitic clays that consist of a 1:1-type clay mineral with one tetrahedral sheet and one octahedral sheet depending on the geological and weathering conditions.

In geopolymer cement, Al plays an important role because of its availability of aluminum controls to a large degree of the geopolymer properties (Duxson et al., 2007; Fernández-Jiménez, 2006). The absolute amount of available aluminum and the rate of its release throughout reaction not only affect final strength, but other properties in the wet and hardened states including setting characteristics, flexural strength, acid resistance, microstructure, and strength development profile. Generally, there are about $10 \%$ aluminum oxide in slag and $40 \%$ in metakaolin. According to the differences in the hydration products and, obviously, the role of $\mathrm{Al}$ in these two systems is different. Alonso and Palomo (2001-a,b) found that with the highly alkaline activation of metakaolin in the presence of calcium hydroxide led to the formation of an amorphous sodium aluminosilicate, which has the same properties of geopolymeric gel. This 
geopolymeric gel formed was found to be similar to that obtained when metakaolin was activated in the absence of calcium hydroxide. CSH gel was also formed as a secondary product when metakaolin was activated in the presence of calcium hydroxide. The high water demand of the reacting mixes and the high surface area and particle shape of MK due to calcination (Provis et al., 2010), affect the mechanical strength development and stability of these materials, which does not always compare well with the performance of other alkali activated binders based on industrial by-products, such as granulated blast furnace slag (GBFS) or with lower cost and higher potential for large-scale industrial applications than MK. Other than the lower aspect ratio of the particles, the main difference between these precursors is the presence of calcium in the GBFS which leads to the development of a microstructure enriched with stable and high density phases such as C-S-H gels, which promotes high compressive strengths (Lecomte et al., 2006; Lloyd, 2009).

The main purpose of this work is to study the preparation of geopolymer materials by alkaline activation of amorphous water cooled slag and different ratios of MK materials. However, MK is not commonly used in most construction cases due to the relatively large specific surface area, which may demand high water/binder ratio to achieve satisfying workability. This means that such a family of abundant resource is not utilized in large volume in geopolymer concrete. So, in the present work the ratios of MK which will be added are less than $20 \%$ of the total mass, because of the used metakaolin was very fine with average pore structure less than $30 \mathrm{~m} \mu$, which hinders the geopolymerization reaction if used as high ratio.

The effect of addition of different ratios of MK on alkali activated slag will be investigated as well as the impacts on mechanical and microstructural characteristics. X-ray florescence, X-ray diffraction, FTIR and SEM were used to identify the chemical, mineralogical and micro-structure of geopolymer composites. The compressive strength measurement was executed to evaluate the mechanical performance of the geopolymer specimens.

\section{Experimental procedures}

\subsection{Materials}

Materials used in this work were metakaolin prepared from kaolin collected from Sinai, West of Gebel Gunna, Egypt; water cooled slag also called ground granulate blast furnace slag (GGBFS) sourced from Iron and Steel Factory- Helwan, Egypt. Sodium hydroxide $(\mathrm{NaOH})$ with purity 98 $\%$ in the form of pellets and sodium silicate $\left(\mathrm{Na}_{2} \mathrm{SiO}_{3}\right.$ ) are used as alkali activators. $\mathrm{MK}$ was prepared by firing kaolin at $750{ }^{\circ} \mathrm{C}$ for $2 \mathrm{~h}$ with heating rate of $5^{\circ} \mathrm{C} / \mathrm{min}$. The chemical composition of the starting raw materials is tabulated in Table (1).

Table 1. Chemical composition of the starting raw materials (Mass, \%)

\begin{tabular}{|c|c|c|}
\hline Materials & Water cooled slag (GGBFS) & Metakaolin \\
\hline \hline $\mathrm{SiO}_{2}$ & 35.63 & 56.00 \\
\hline $\mathrm{Al}_{2} \mathrm{O}_{3}$ & 12.69 & 38.11 \\
\hline $\mathrm{Fe}_{2} \mathrm{O}_{3}$ & 0.48 & 0.48 \\
\hline $\mathrm{CaO}$ & 31.72 & 0.21 \\
\hline $\mathrm{MgO}$ & 5.08 & 0.37 \\
\hline $\mathrm{SO}_{3}$ & 2.35 & 0.18 \\
\hline $\mathrm{Na}_{2} \mathrm{O}$ & 1.23 & 0.00 \\
\hline $\mathrm{K}_{2} \mathrm{O}$ & 1.52 & 0.02 \\
\hline $\mathrm{TiO}_{2}$ & 0.55 & 1.14 \\
\hline $\mathrm{P}_{2} \mathrm{O}_{5}$ & 0.031 & 0.26 \\
\hline $\mathrm{MnO}$ & 4.72 & 0.00 \\
\hline $\mathrm{Cl}$ & 0.24 & 0.00 \\
\hline Loss & 0.03 & 3.13 \\
\hline TOTAL & 99.89 & 99.89 \\
\hline Note & $\mathrm{BaO}=3.63$ & \\
\hline
\end{tabular}


The major components of GGBFS are $\mathrm{SiO}_{2}, \mathrm{CaO}, \mathrm{Al}_{2} \mathrm{O}_{3}$ and $\mathrm{MgO}$. While in metakaolin, the two major components are $\mathrm{SiO}_{2}$ and $\mathrm{Al}_{2} \mathrm{O}_{3}$. Table 2 summarizes the major chemical composition of GGBFS and metakaolin (Buchwald et al., 2007; Li \& Ding, 2003; Cheng \& Chiu, 2003). From the chemical composition, we can consider that GGBFS is ( $\mathrm{Si}+\mathrm{Ca}$ ) system and ( $\mathrm{Si}+\mathrm{Al})$ is suitable for MK. Generally, GGBFS contains massive glass phase, while some crystalline phases may exist in minor level, such as gehlenite and akermanite. On the other hand, MK is ideally synthesized by dehydroxylation of phase pure kaolin while most commercial MK contains levels of impurities, primarily muscovite and titanium dioxide.

Laser particle size distribution of Mk reflected its very fine pore structure. This mean most particle size lower than $30 \mathrm{~m} \mu$ as indicated in Fig. 1.

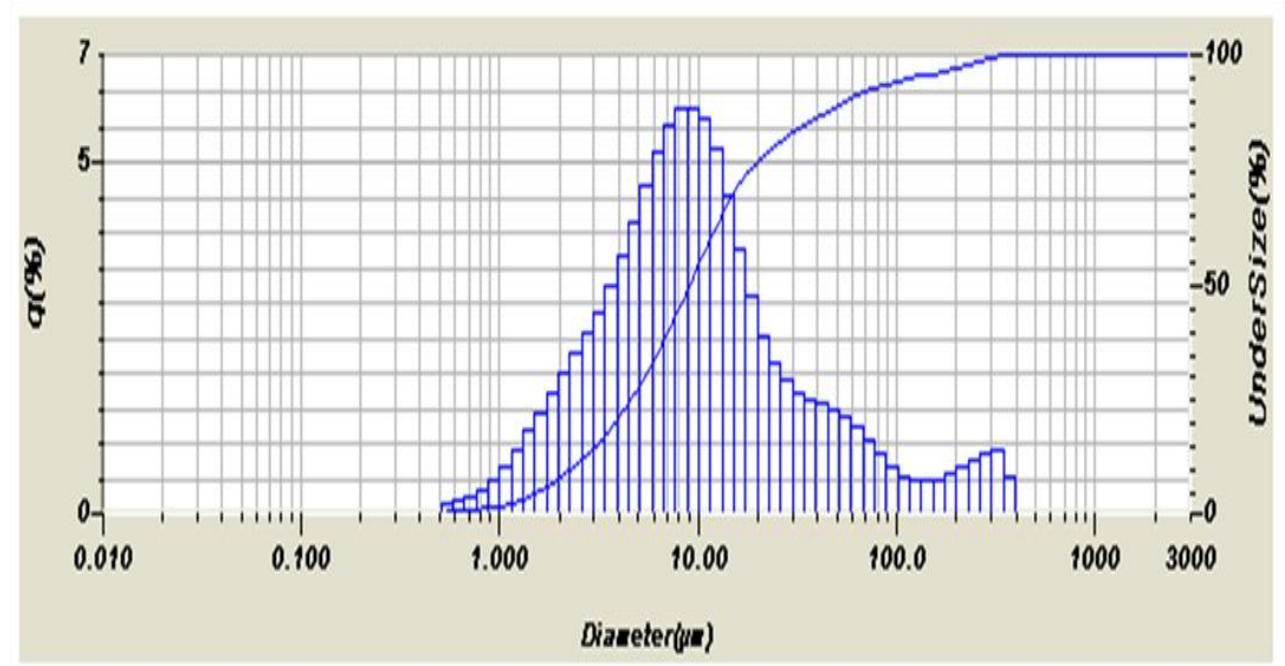

Fig. 1. Laser particle size distribution of Mk.

Mineralogical characterization of the raw materials was done using X-ray diffraction analysis in powder form as represented in Fig. 2.

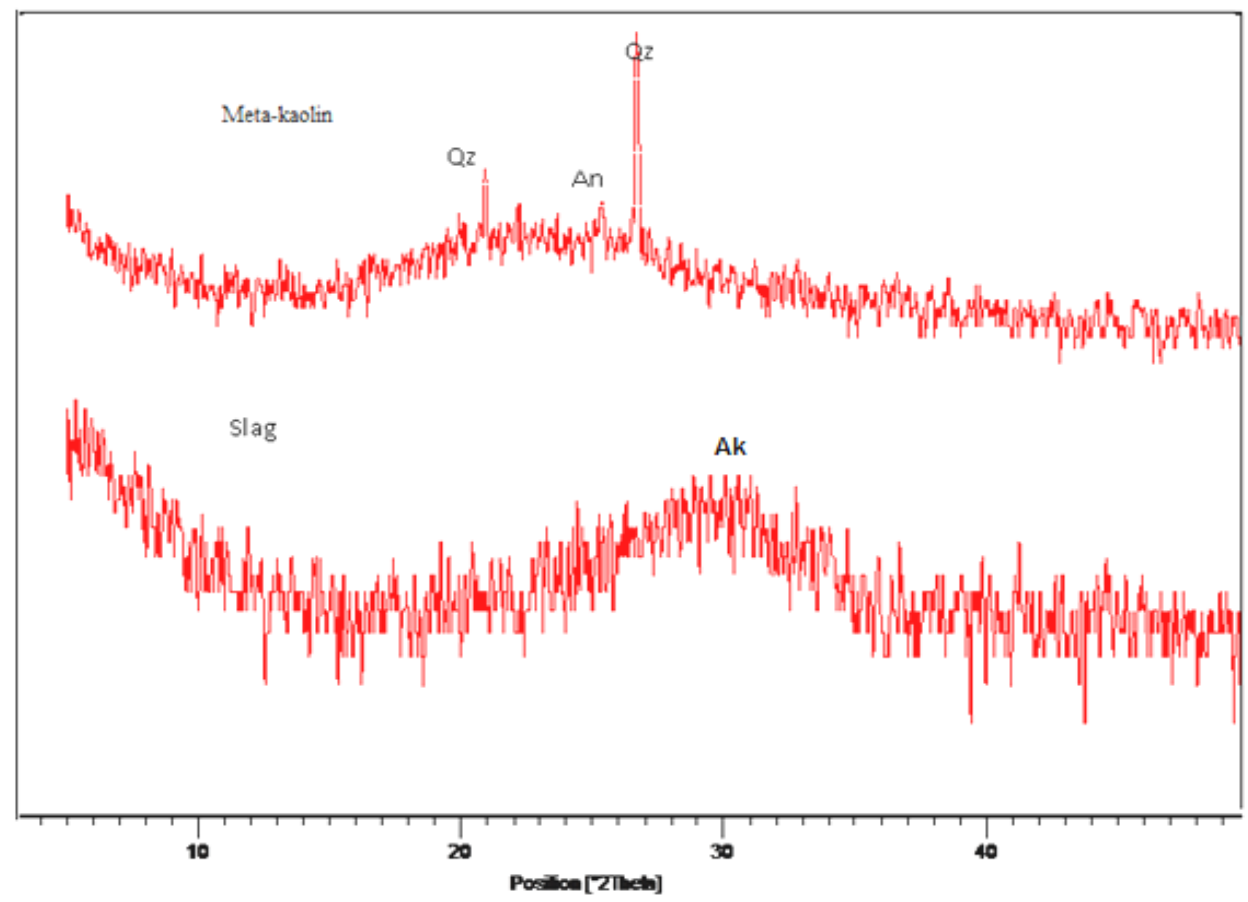

Fig. 2. X-ray differaction pattern for the starting raw materials. [Qz: Quartz An: Anataze Ak:Akermanite] 
The patterns show that GGBFS composed mainly of glassy phases and few crystalline material of akermanite (Ca2MgSi207), while MK material is composed of quartz and anataze minerals

\subsection{Geopolymerization and curing}

Geopolymer was made by hand-mixing raw materials of each mixture with the alkaline solution for $5 \mathrm{~min}$ and a further $5 \mathrm{~min}$ in a mixer. MK was mixed with the GGBFS in ratios as illustrated in Table (2). The water binder material ratio (w/c) was different from 0.28 to $0.38 \%$ by mass, the other part of water was mixed with the $6 \%(\mathrm{NaOH})+6 \%\left(\mathrm{Na}_{2} \mathrm{SiO}_{3}\right)$ alkali activators. Paste mixture were cast into $25 \times 25 \times 25 \mathrm{~mm}$ cubic shaped moulds, vibrated for compaction and sealed with a lid to minimize any loss of evaporable water.

All mixes were left to cure at ambient temperature for $24 \mathrm{~h}$, and then subjected to curing temperature of $38{ }^{\circ} \mathrm{C}$ and $100 \%$ relative humidity. The crushed specimens which obtained from compressive strength test were subjected to stopping of the hydration process by drying at 105을 for $24 \mathrm{~h}$ (Bakharev, 2006) and then preserved in a well tight container until the time of testing.

Table 2. Mix design of MK and GGBFS materials.

\begin{tabular}{|c|c|c|c|c|c|}
\hline Mix & $\begin{array}{c}\text { Meta- } \\
\text { Kaolin, } \%\end{array}$ & $\begin{array}{c}\text { Slag, } \\
\%\end{array}$ & $\begin{array}{c}\mathrm{NaOH}, \\
\%\end{array}$ & $\begin{array}{c}\text { Na2SiO3, } \\
\%\end{array}$ & $\begin{array}{c}\mathrm{W} / \mathrm{C} \\
\%\end{array}$ \\
\hline $\mathrm{A}$ & 0 & 100 & 6 & 6 & 0.34 \\
\hline $\mathrm{B}$ & 5 & 95 & 6 & 6 & 0.34 \\
\hline $\mathrm{C}$ & 10 & 90 & 6 & 6 & 0.36 \\
\hline $\mathrm{D}$ & 15 & 85 & 6 & 6 & 0.38 \\
\hline $\mathrm{E}$ & 20 & 80 & 6 & 6 & 0.38 \\
\hline
\end{tabular}

These hardened materials were characterized using XRF, XRD, FTIR, and SEM. The instrumental conditions used are shown below:

Chemical analysis was carried out using Axios, WD-XRF Sequential Spectrometer (Panalytical, Netherland, 2009). XRD analysis was carried out using a Philips PW3050/60 Diffractometer. The data were identified according to the XRD software. Perkin Elmer FTIR Spectrum RX1 Spectrometer was used to evaluate the functional groups in the sample. Small amount of potassium bromide $(\mathrm{KBr})$ and geopolymer powder were put into a mould with $\mathrm{KBr}$ pellets and pressed at $295 \mathrm{MPa}$ for 2 min to produce specimen for examination, The wave number was ranged from 400 to $4000 \mathrm{~cm}^{-1}$ (Panias et al., 2007; Bakharev, 2006).

Compressive strength tests were carried out using five tones German Brüf pressing machine with a loading rate of $100 \mathrm{~kg} / \mathrm{min}$ determined according to ASTM-C109-07 (2007). The microstructure of the hardened specimens was studied using SEM Inspect S (FEI Company, Netherland). The removal free water was accomplished by drying at $105^{\circ} \mathrm{C}$ for $24 \mathrm{~h}$ (Bakharev, 2006).

\section{Results and discussion}

\subsection{Mineralogical investigation}

XRD patterns of 90 days of alkali-activated slag specimens incorporating various ratios of MK activated by sodium hydroxide and sodium silicate in the ratios illustrated previously in table (2).The XRD patterns of alkali activated slag pastes with $0 \%, 5 \%, 10 \%, 15$ and $20 \%$ MK replacement are shown in Fig. 3.

The main reaction products of all mixes are amorphous phases except small amount of crystalline phases that obtained from the raw materials such as quartz. Also, CAH was detected 
as a result phase of slag geopolymerization. The amorphous phases with humps ranging from $25^{\circ}$ to $35^{\circ} 2 \theta$ can be regarded as a result of glassy phase of slag geopolymerization progress.

On the other hand, the agglomerated MK results in an increased porosity as well as increased carbonation within the matrix as indicated in calcite peak at $29.35^{\circ} 2 \theta$, more clear in specimens $15 \%$ and $20 \%$ MK. As the slag content continues to decrease, the intensity peaks at around $30^{\circ} 2 \theta$ decrease, which represents the formation of C-S-H type gel from alkali activated slag. The intensity peaks that represent C-S-H gel were more significant in control specimen with higher slag content.

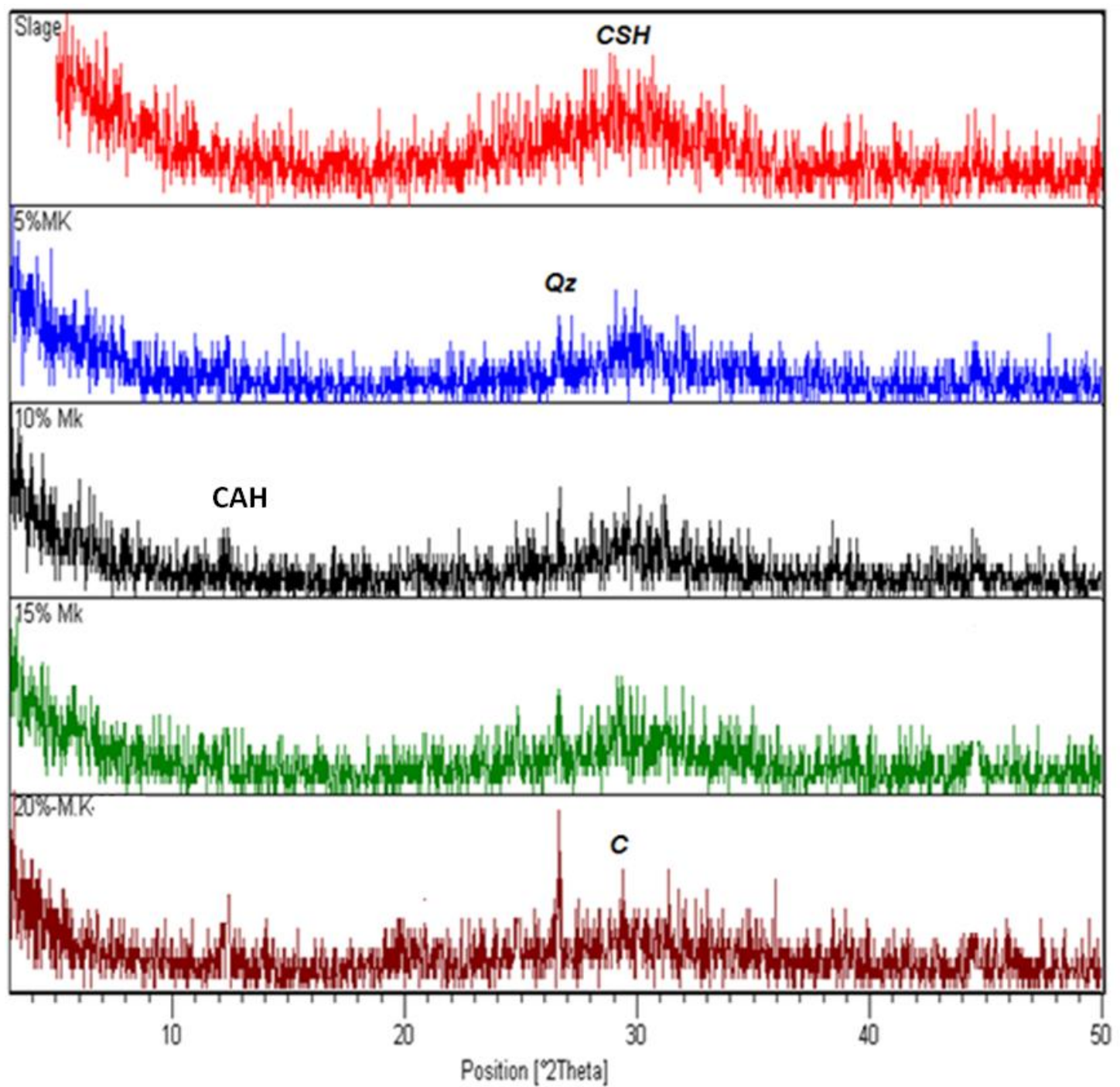

Fig. 3. The XRD patterns of slag-MK blends cured at 90 days. [Qz: Quartz, CAH: Calcium aluminate hydrate CSH: Calcium silicate hydrate, C: Calcite]

\subsection{Scanning electron microscopy (SEM)}

The scanning electron micrograph of 90 days geopolymer specimens having various MK ratios are shown in Fig. 4. Its noticed that the microstructure of $10 \%$ MK displayed compaction of matrix with the presence of geopolymer gel which filled the pores of the matrix specimens, as compared to the less dense structure 5 and $20 \%$ of MK percentages of dry mixes. Substitution of slag by $10 \%$ MK leads to the enhancement in the morphological structure of the resulting geopolymer chains. 
The added MK resulted in exceeds of amorphous alumino-silicate structure that enrich the morphological shape and leads to the enhancement in mechanical properties as revealed previously in the compressive strength results.
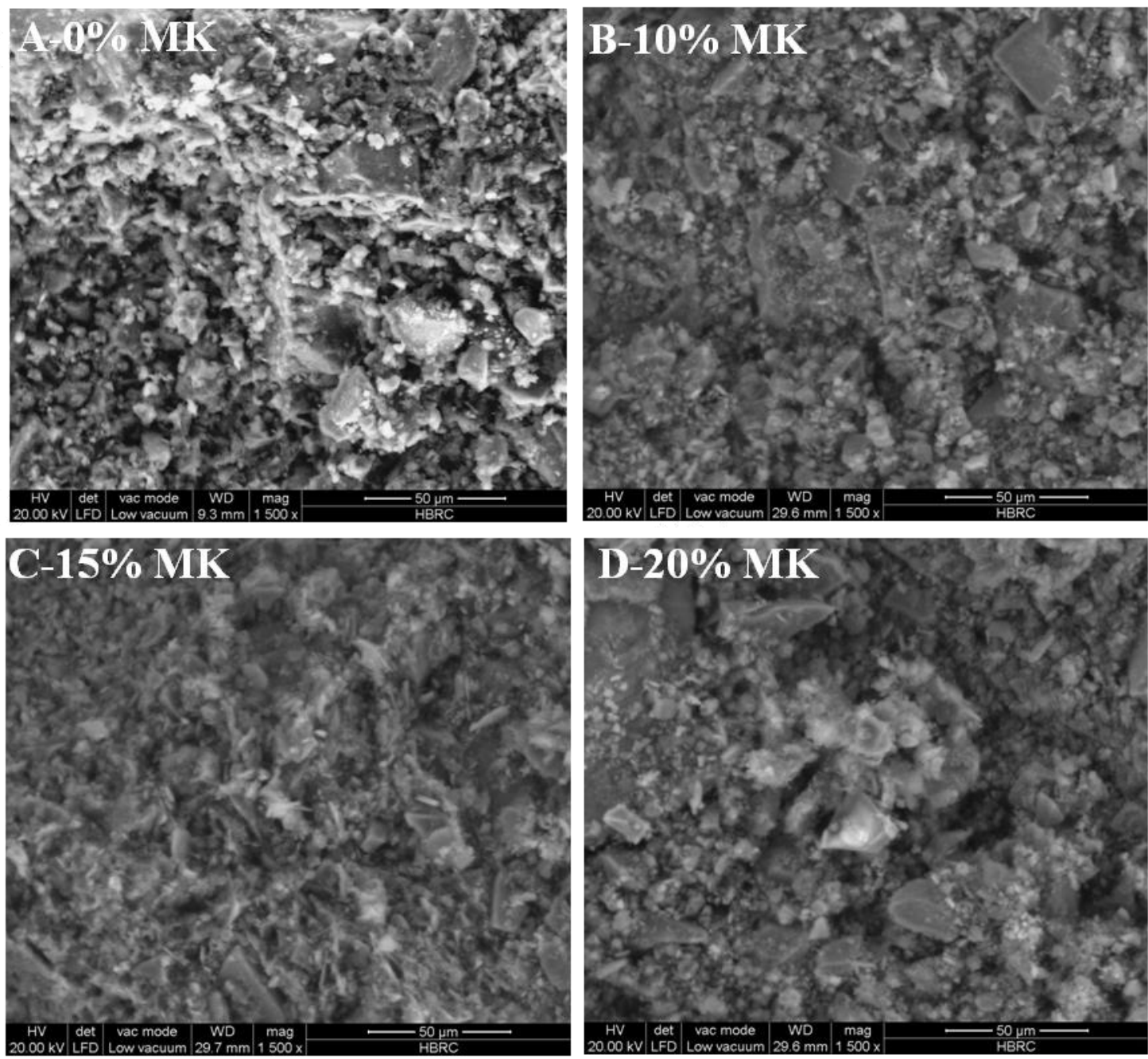

Fig. 4. The scanning electron micrograph of geopolymer specimens of slag and MK materials cured at 90 days.

The alkaline activation of MK is believed to be a surface reaction, with silicate and aluminate species dissociated from the surface of MK (Yunsheng et al., 2010). This phase was found to have no regular shape or morphology and the particles in (Fig. 4, B) appear broken than a platy shape.

The large surface area of MK and their abundance because of their small size can facilitate the chemical reactions necessary to produce a dense cement matrix with more calcium silicate hydrate (C-S-H) and less calcium hydroxide. On the other hand adding $20 \%$ MK lead to the formation of agglomerate which hinders the intact between the reacting materials as shown in (Fig. 4, D).

\subsection{Fourier Transform Infrared FTIR spectroscopy}

FTIR spectra of 90 days cured geopolymer specimens having metakaolin content as a partial replacement of slag are shown in Fig. (5). The characteristics bands for the present geopolymer structure are: hydration groups and combined water allocated for stretching vibration of $\mathrm{O}-\mathrm{H}$ bond at about $3500 \mathrm{~cm}^{-1}$ and bending vibration for $\mathrm{HO}-\mathrm{H}$ at about $1650 \mathrm{~cm}^{-1}$, stretching vibration of $\mathrm{CO}_{2}$ located at about1440-1450 $\mathrm{cm}^{-1}$, asymmetric stretching vibration ( $\mathrm{Si}-\mathrm{O}-\mathrm{Si}$ ) at about $1050 \mathrm{~cm}^{-1}$ for non-solublized silica, asymmetric stretching vibration (Ti-O-Si) at about 
$970-1000 \mathrm{~cm}^{-1}$ where $\mathrm{T}=\mathrm{Si}$ or $\mathrm{Al}$, symmetric stretching vibration (Al-O-Si)between 740-770 $\mathrm{cm}^{-1}$ and bending vibration (Si-O-Si and $\mathrm{O}-\mathrm{Si}-0$ ) in the region $440-450 \mathrm{~cm}^{-1}$.

Also the main asymmetric band around $1000 \mathrm{~cm}^{-1}$ turned to be wider with the increase of the added slag up to $90 \%$ reflecting the increase of the geopolymerization reaction.

CASH at $685 \mathrm{~cm}^{-1}$ for the hydration phases resulted from amorphous slag especially in $10 \% \mathrm{MK}$ specimen and decrease up to $20 \% \mathrm{MK}$. Also, it is noticed that non-solublized silica decreased in $10 \%$ MK specimen but obviously appears when GGBFS replaced by $15 \%$ and $20 \%$ MK. The weak band observed around $840 \mathrm{~cm}-1$ on 5\%,15\% and 20\% MK specimens is assigned to the bending vibration of $\mathrm{Si} \mathrm{OH}$. The presence of $\mathrm{Si} \mathrm{OH}$ in the geopolymer products will lead to decrease the degree of polycondensation reaction, thus a reduction in mechanical strength (Yunsheng et al., 2010).

The main asymmetric band for T-O-Si shifted to higher wave number with increasing MK more than $10 \%$ because of adding MK with its fine pore structure hinder propagation of geopolymer chain.

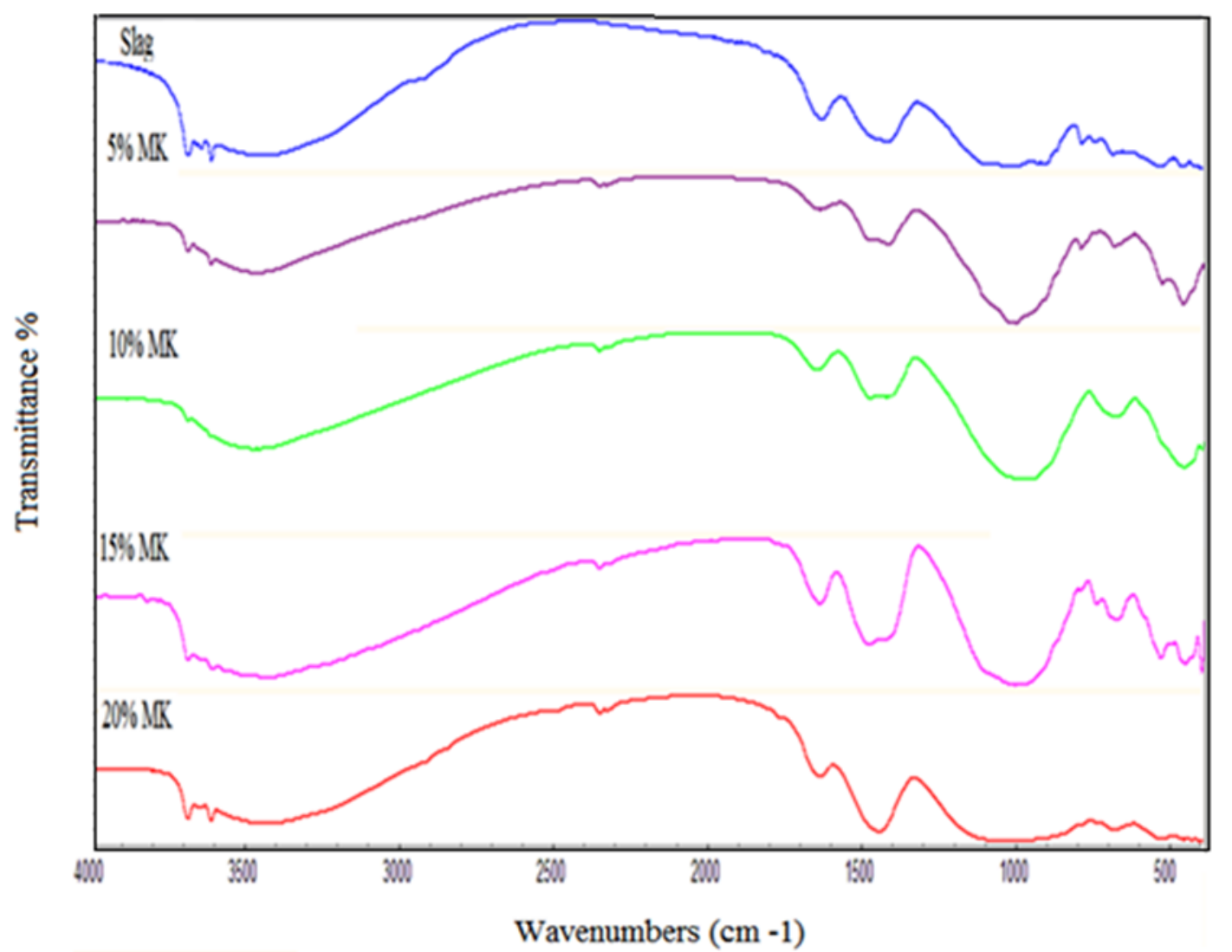

Fig. 5. FTIR spectra of geopolymer specimens of water cooled slag having various Mk percentages cured at 90 days.

\subsection{Compressive Strength}

Results of the compressive strength for geopolymer mixes along with cured at $100 \%$ relative humidity and at $38^{\circ} \mathrm{C}$ up to 90 days are shown in (Fig. 6).The results show the increase of strength in all mixes along with hydration age up to 90 days.

From Fig. 5 , it can be seen that when the replacement percentage is $10 \%$ meta-kaolin, maximum strength is obtained. In other word, as the amount of MK increases up to $20 \%$ the compressive strength is accordingly decreases, because of increasing dose of MK with its fine pore structure 
leads to the formation of agglomerate which increased porosity and hinders the intact between the reacting materials.

Replacing glassy slag by amorphous MK results in the formation of more homogeneous matrix, also there is coexistence of geopolymer chains along with CSH binding gel that acts as seeding agent for geopolymer accumulation and so results in a more compact and dense structure, this effect will decrease with increasing $\mathrm{MK}$.

The geopolymer manufactured only from $100 \%$ slag as a control mix was found to have the highest early strength while that from slag and MK was found to has the highest lately strength and better than $100 \%$ of slag control sample especially which has $10 \%$ and $15 \%$ MK.

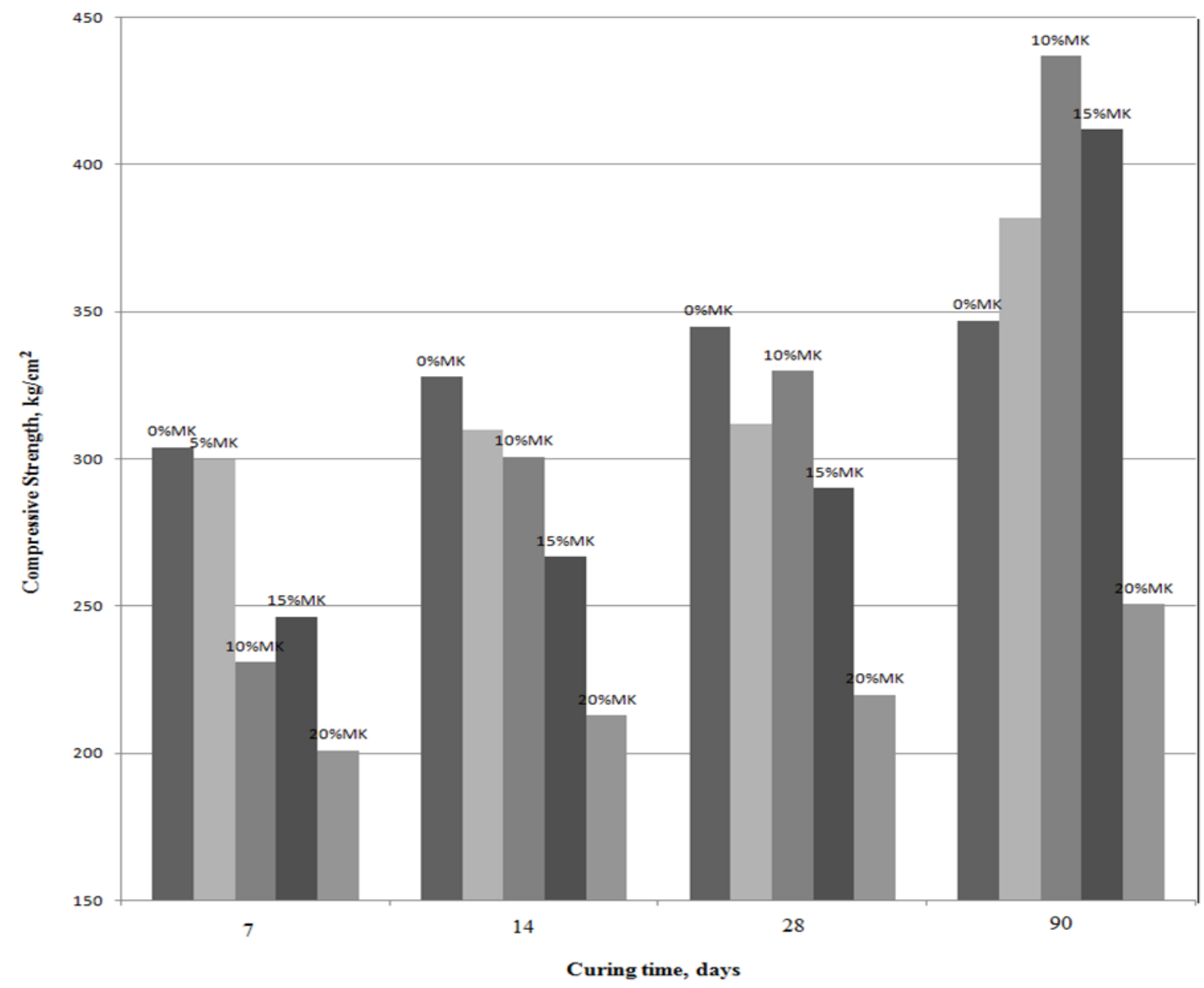

Fig. 6. Compressive strength of geopolymer specimens of water cooled slag having various Mk percentages cured at 90 days.

Generally, mechanical strength improvement with the inclusion of calcium has been reported, the main binding phases in the microstructure are alkali alumino-silicate gel and Al-substituted calcium silicate hydrate (C-S-H) gel. For MK/GGBFS blends, it has been identified that the mechanism of activation is highly dependent on both the alkalinity of the alkali activator and the ratio between MK and GGBFS, which act together to control the rate of $\mathrm{Ca}^{2+}$ dissolution and availability during the reaction (Xu \& Van Deventer, 2000).

\subsection{Water Absorption}

The water absorption of all samples (Fig. 7) decreases with increase of curing time, in opposing to compressive strength. Also, the water absorption decreases up to $10 \% \mathrm{MK}$ up to 90 days of curing in all of the mixes. The geopolymer gel formed at $10 \% \mathrm{MK}$ results in a decrease in the 
porosity of the matrix and as well as water absorption, while on using $20 \%$, the fine structure and high surface area of added metakaolin, requires higher amount of water and thus cause increase in the porosity of resultant geopolymer

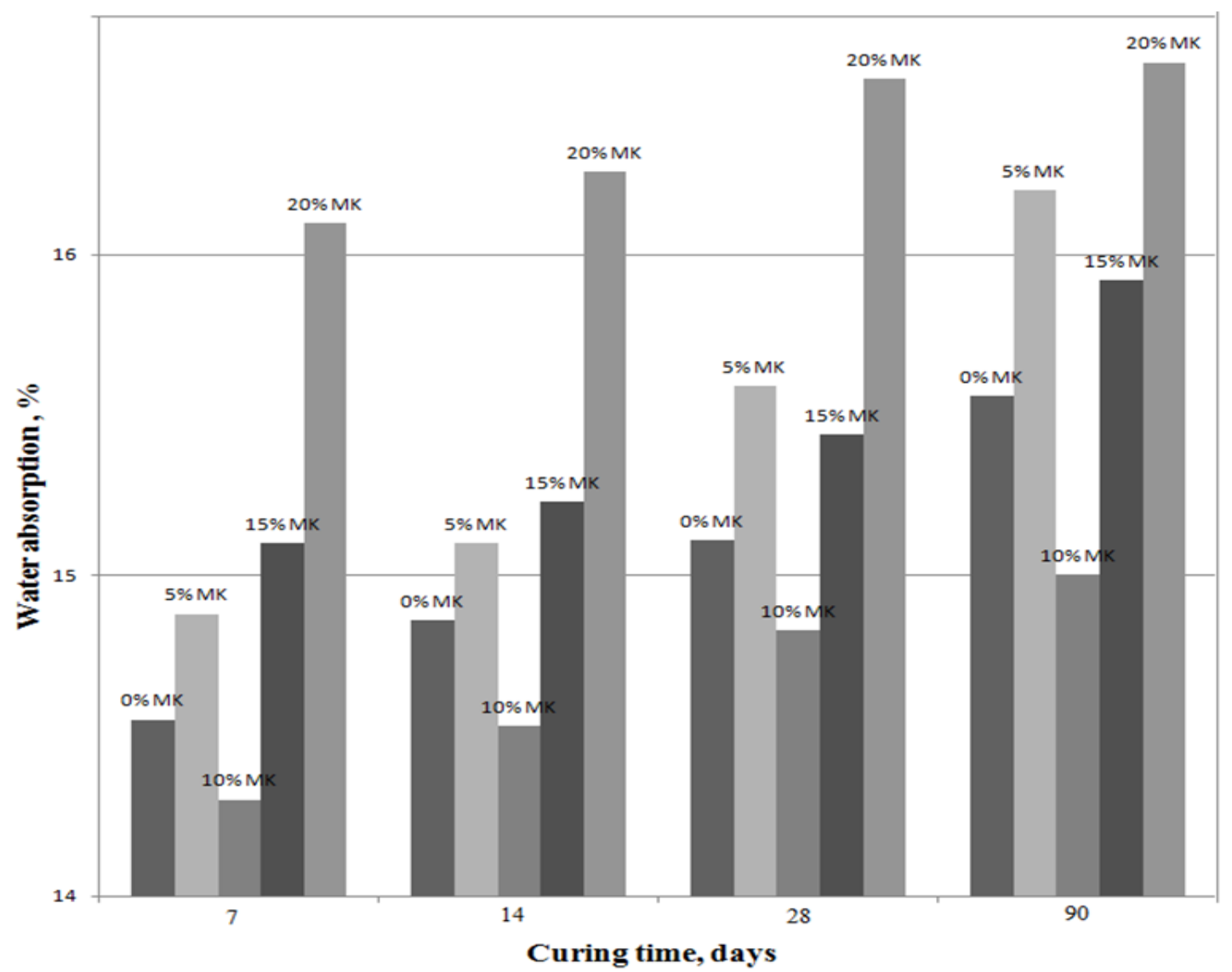

Fig. 7. Water absorption of geopolymer specimens of water cooled slag having various Mk percentages cured at 90 days.

\section{Conclusion}

Addition of different percentages of meta-kaolin improves mechanical and microstructural properties, where:

1. Addition of metakaolin provided an enhancement in geopolymer microstructure and results in the formation of well compacted dense structure.

2. FTIR spectra confirm the intense amorphous geopolymer structure up on using $10 \%$ metakaolin, while the increased crystalline phases are predominant with further metakaolin increase.

3. The compressive strength increase with increasing percentages of metakaolin up to $10 \%$, increasing dose of metakaolin leads to the formation of agglomerate which hinders the intact between the reacting materials

4. The geopolymer manufactured only from $100 \%$ slag as a control mix was found to has the highest early strength while that formed from slag and metakaolin was found to has the highest lately strength and better than $100 \%$ of slag control sample especially which has $10 \%$ and $15 \%$ metakaolin.

5. In order to obtain good and low cost alkali activated geopolymer slag-metakaolin binding materials, metakaolin should be added in percent lesser than $20 \%$ of the total mass. 


\section{ACKNOWLEDGEMENTS}

The authors gratefully acknowledge Prof. Hisham M. Khater from Housing and Building National Research Centre (HBRC) for supporting and comments.

\section{References}

Alonso, S., \& Palomo, A. (2001-a). Alkaline activation of metakaolin and calcium hydroxide mixtures: influence of temperature, activator concentration and solids ratio. Materials Letters, 47(1-2), 55-62.

Alonso, S., \& Palomo, A. (2001-b). Calorimetric study of alkaline activation of calcium hydroxidemetakaolin solid mixtures. Cement and Concrete Research, 31(1), 25-30.

ASTM C109M- 07. (2007).Standard test method for compressive strength of Hydraulic Cement Mortars.

Bakarev, T. (2006).thermal behavior of geopolymer prepared using class F fly ash and elected temperature curing. Cement and concrete Research; 36:1134-1147.

Bakharev, T. (2006). Thermal behaviour of geopolymers prepared using class $\mathrm{F}$ fly ash and elevated temperature curing. Cement and Concrete Research, 36(6), 1134-1147.

Buchwald, A., Hilbig, H., \& Kaps, C. (2007). Alkali-activated metakaolin-slag blends-performance and structure in dependence of their composition. Journal of materials science, 42(9), 3024-3032.

Cheng, T. W., \& Chiu, J. P. (2003). Fire-resistant geopolymer produced by granulated blast furnace slag. Minerals engineering, 16(3), 205-210.

Davidovits, J. (1999). Chemistry of Geopolymeric Systems [C]. In CORDI-Geopolymer. Terminology, Geopolymer 99 Proceedings: $2^{\text {nd }}$ International Conference, Saint Quentin (pp. 1-2).

Davidovits, J. (2008). Geopolymer Chemistry and Applications. 2nd. Institute Geopolymere, France, 333365.

Duxson, P., Fernández-Jiménez, A., Provis, J. L., Lukey, G. C., Palomo, A., \& van Deventer, J. S. (2007). Geopolymer technology: the current state of the art. Journal of materials science, 42(9), 2917-2933.

Fernández-Jiménez, A., Palomo, A., Sobrados, I., \& Sanz, J. (2006). The role played by the reactive alumina content in the alkaline activation of fly ashes. Microporous and Mesoporous materials, 91(1-3), 111119.

Hardjito, D., Wallah, S. E., Sumajouw, D. M. J., \& Rangan, B. V. (2004). Brief review of development of geopolymer concrete. In $8^{\text {th }}$ CANMET/ACI International Conference on fly ash, silica fume, slag and natural pozzolans in concrete. Las Vegas (USA).

Lecomte, I., Henrist, C., Liégeois, M., Maseri, F., Rulmont, A., \& Cloots, R. (2006). (Micro)-structural comparison between geopolymers, alkali-activated slag cement and Portland cement. Journal of the European Ceramic Society, 26(16), 3789-3797.

Li, Z., \& Ding, Z. (2003). Property improvement of Portland cement by incorporating with metakaolin and slag. Cement and concrete research, 33(4), 579-584.

Lloyd, R.R. (2009). Accelerated ageing of geopolymers. In: Provis JL, van Deventer JSJ (eds). Geopolymers: Structures, Processing, Properties and Industrial Applications. Woodhead, Cambridge, UK, pp. 139166.

Panias, D., Giannopoulou, I. P., \& Perraki, T. (2007). Effect of synthesis parameters on the mechanical properties of fly ash-based geopolymers. Colloids and Surfaces A: Physicochemical and Engineering Aspects, 301(1-3), 246-254. 
Provis, J. L., Duxson, P., \& van Deventer, J. S. (2010). The role of particle technology in developing sustainable construction materials. Advanced Powder Technology, 21(1), 2-7.

Steveson, M., \& Sagoe-Crentsil, K. (2005). Relationships between composition, structure and strength of inorganic polymers. Journal of materials science, 40(8), 2023-2036.

Xu, H., \& Van Deventer, J. S. J. (2000). The geopolymerisation of alumino-silicate minerals. International journal of mineral processing, 59(3), 247-266.

Yunsheng, Z., Wei, S., \& Zongjin, L. (2010). Composition design and microstructural characterization of calcined kaolin-based geopolymer cement. Applied Clay Science, 47(3-4), 271-275. 